\title{
Una luminosa vitalidad para la literatura latinoamericana contemporánea: entrevista a Gabriela Cabezón Cámara
}

Carlos Hernán Sosa Universidad Nacional de Salta-CONICET

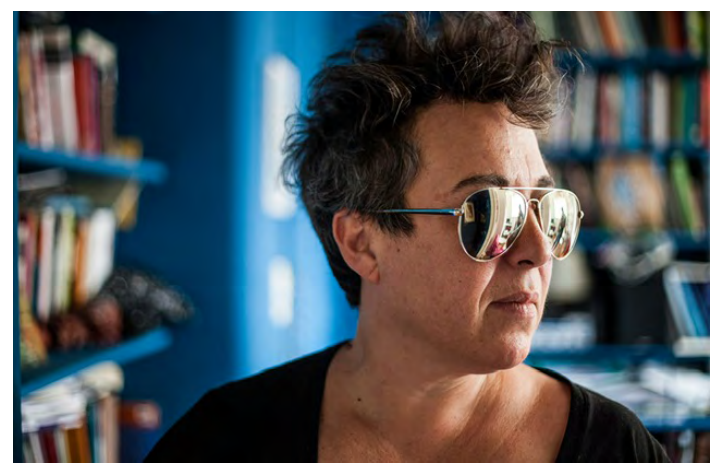

En los últimos veinte años, la escritora argentina Gabriela Cabezón Cámara (San Isidro, 1968) ha afianzado una importante trayectoria en el ámbito literario, especialmente en el terreno de la narrativa, y el periodístico, en medios independientes. Estudió Letras en la Universidad de Buenos Aires, y fue escritora residente en la Universidad de California, en Berkeley (2013). Sostiene una intensa actividad dictando talleres y clínicas de escritura, y realizando tareas de producción y edición en el periodismo cultural (en medios gráficos como las revistas Anfibia y Fierro y el diario Página 12). Ha publicado las novelas La Virgen Cabeza (2009) y Las aventuras de la China Iron (2017), las nouvelles Le viste la cara a Dios (2011) y Romance de la Negra Rubia (2014), el volumen de relatos Sacrificios (2015) y las novelas gráficas Beya (Le viste la cara a Dios) (2011) e Y su despojo fue una muchedumbre (2015), ambas ilustradas por Iñaki Echeverría.

A continuación, compartimos una charla que mantuvimos con ella sobre diversos aspectos de la trascendencia de la literatura en su vida.

Gabriela, quería empezar hablando de tu ingreso a la literatura como lectora y escritora. Al recordar tu experiencia, ¿cómo pensás un relato posible de esa historia?, ¿qué particularidades tendría?, ¿qué momentos (hitos-vaivenes-continuidades) podrías reconocer?

Mi ingreso a la literatura como lectora y escritora supongo que es como el de todo el mundo: la fascinación por las historias, por esos mundos otros más brillantes y coloridos que los que yo conocía, la "interlocución" -así lo sentía cuando nena y, bueno, ahora también- con personas muy interesantes y cierta tendencia a la introspección, cierta incomodidad con lo que me rodeaba que me llevaba a querer inventar otros entornos, a fantasear mundos otros. Así fue mi ingreso, hace un montón de años, cuando era una nenita. No recuerdo hitos particulares, excepto tal vez, la primera vez que tuve libros. En mi casa natal no había libros, mis viejos no tenían ninguna clase de objeto que no consideraran de muy primera necesidad. Hasta que vieron que a mí me gustaban y entonces me compraron una colección de libritos ilustrados de tapa dura, de la editorial Sigmar, eran versiones para niños de clásicos de los Grimm, Perrault y también de Las mil noches y una noche. Luego 
descubrí la biblioteca Robin Hood de mi abuela, unos cuarenta o cincuenta libros, me parecía la biblioteca de Alejandría. A los ocho años leí el primero de esos, Las aventuras de Tom Sawyer, me sentí muy orgullosa de leer un libro largo y sin ilustraciones. En cuanto a la escritura, más o menos lo mismo. Empecé en la escuela, y bueno, me gustó y seguí. Aunque, por supuesto, la mayor parte de mi vida fue mucho, mucho más, lo que leí que lo que escribí.

Durante esos avatares como lectora, ¿encontraste escritores cómplices, es decir, aquellos que sintonizan o se aproximan en alguna medida a tus modos de pensar la escritura o las prácticas cercanas a lo literario? ¿Esas personas y sus producciones se vinculan de algún modo con tu quehacer de escritora?

¿Hablamos de escritores vivos y con los que comparto espacios? Siento complicidad con todos los que me parecen buenas personas; la literatura es pasión fuerte y compartirla genera lazos. Escritores cómplices, qué decirte; muchos, muchísimos. De hecho, compartir la pasión por escribir suele establecer una complicidad: estás parada en un campo común con esos otros, sean señores consagradísimos o chicos de 20 veinte años que están empezando. Esa forma de ver el mundo que te da escribir es un montón de complicidad. Después, cuentan también las afinidades personales, que pueden o no ser estéticas. Me siento cerca de muchos colegas, muchos son mis amigos.

En relación con estas complicidades, desde las últimas dos décadas, un grupo importante de escritoras argentinas en una franja de edades más o menos cercana (pienso en vos, Samanta Schweblin, Mariana Enriquez, Selva Almada, entre otras) alcanzaron gran trascendencia en Argentina y fuera del país también. En principio, y creo que es lo más importante, porque son muy leídas, pero también porque tuvieron presencia sostenida en ferias de libros internacionales, participaron en el circuito de premios literarios y recibieron la lectura especializada de la crítica. ¿Cómo evaluás esta situación general y tu participación en ella?

Creo que sí, que es como vos decís, en los últimos años las mujeres somos más editadas y leídas que, por ejemplo, en la década del ‘90, por no ir más atrás. Tanto en Argentina como en otros países, aunque sigue siendo muy dispar el acceso a la publicación o a las ferias. De todos modos, sin lugar a dudas, el espacio es mayor que hace un par de décadas. Es una situación grata para mí, me encanta encontrarme con otras autoras, incluso con amigas, cuando me toca ir a ferias y festivales. Decir que son mega talentosas y que se lo merecen es una obviedad. También lo eran, por nombrar algunas, Libertad Demitrópulos, Sara Gallardo y Elena Garro, y no recibieron el reconocimiento que merecían. En lo personal, agradecimiento y alegría siento, cuando los lectores se me acercan o la crítica me dedica algo de su atención.

Hablando del mercado editorial, ifue dificultoso para vos incorporarte, sobre todo al gestionar tus primeros libros? Por el contrario, tener actualmente el reconocimiento por una trayectoria sostenida como escritora ¿condiciona de alguna manera tus proyectos a futuro? 
No, fue muy sencillo para mí la publicación de la primera novela que logré terminar de escribir, La Virgen Cabeza. María Moreno le recomendó a Leonora Djament, editora de Eterna Cadencia, que la leyera. Le llevé una impresión hermosamente anillada. A los quince días me escribió y me dijo que la publicaba y que le haga un final. Yo tenía ya treinta y nueve años en ese momento, tal vez por eso me fue fácil. La facilidad fue inversamente proporcional a lo que me costó creer en que "esas cositas" que yo escribía podían interesarle a alguien más, que podía encontrar lectores, que podía hacer eso, justamente eso que yo quería hacer y ninguna otra cosa. En la actualidad no siento ninguna presión en particular. A veces, siento miedo de que nunca más se me ocurra otra idea. O de copiarme a mí misma, de hacer siempre lo mismo. Pero bueno, por ahora se me ocurren las ideas y trabajo para no copiarme.

En tu obra édita hay exponentes de la novela y la novela gráfica, es decir, textos que apuestan decididamente por la modalidad narrativa, pero ¿te seducen otros géneros o ensayaste escrituras por carriles diferentes?

Te diría que, curiosamente, lo que más me interesa es la poesía. No necesariamente la que viene cortada en versos, aunque también, claro, sino algo así como toda la poesía, una manera de aproximarse a la lengua que tiene en cuenta su espesor infinito, su filo político, su polisemia interminable, y su música posible, infinita también.

Este último comentario me motiva a preguntarte sobre el proceso creativo de escritura. Uno podría decir que existen tantas formas de tramarlo como escritores que lo ensayan a diario; en tu caso, ¿cuáles son tus rutinas -si las tenés-al pensar y encarar la realización de un proyecto de escritura?

Mi rutina es el fracaso de la rutina: todos los días quiero escribir y casi todos los días algo se interpone. Soy cuentapropista, trabajo mucho y sin horarios y soy mi cadete y mi secretario también $\mathrm{y}$, a veces, incluso mi plomero. No puedo escribir en un ratito libre, necesito tres o cuatro horas libres; trato de concentrar el trabajo en cuatro jornadas para tener después dos para escribir y un día libre. A veces lo logro.

Pasando a algunos aspectos puntuales de tus textos, en Las aventuras de la China Iron se reescribe una tradición machista por excelencia como es la gauchesca argentina, ifue un desafío darle voz e historia propias a una silenciada del Martín Fierro como la China?

Escribir la voz de la China fue una delicia para mí: la empecé con un impulso vital, quería cantar esa voz que no había leído en la gauchesca, quería sustraerla de la suerte de sus muchachos, quería que fuera una mujer libre y plena, que viera el mundo con la voracidad, el brillo y la sensualidad de las primeras miradas, quería que se hiciera un mundo hermoso y para eso, claro, necesité que se saliera de la historia, que empezara otra. Más que un desafío fue un placer, fue habitar un mundo luminoso mientras mucho de mi vida se derrumbaba: esa escritura coincidió en gran parte con la larga agonía de mi papá y otras cuestiones menos graves pero bien complejas y bastante abrumadoras para mí. Las lecturas que yo sentía necesarias para este proyecto ya las había hecho en general, 
pero incorporé otras. Le leí a mi padre, por ejemplo, Usos y costumbres de los indios de la pampa, mientras lo leía yo. Lo más desafiante para mí fue escribir la luz: es un quilombo, no podés poner luz y brillo diez veces por página, en una novela relativamente larga. Trabajé un montón en eso.

En La Virgen Cabeza, hay una puesta en valor de las formas del decir populares, de la oralidad riquísima que eclosiona en las grandes ciudades latinoamericanas, en este caso del conurbano de Buenos Aires, que ingresan con potencia y son un elemento importante de tu novela, ¿cómo gestionaste esas adecuaciones a la escritura?

Respecto de algunos registros de lengua de La Virgen Cabeza, los que tienen que ver con la oralidad popular tienen mucho de homenaje. Cleopatra, por ejemplo, es un homenaje a una amiga de mi adolescencia, Paula, una chica travesti hermosa y brillante, con un sentido del humor exquisito y más calle que casi toda la gente que conocí en mi vida, pese a haber muerto a los 21 años. Lo que viene de la cumbia, bueno, viene de la cumbia, no necesita explicación. De cómo eso se tramó con versos de Petrarca o algo de la estructura de la Odisea, te diría que fue como la vida misma: es lo que tenía en la cabeza cuando escribí La Virgen Cabeza.

Las facetas caleidoscópicas de las mujeres y de lo femenino son un ingreso posible a tu obra, permite leerla en algunas líneas transversales. ¿Esto responde a un programa literario previo sobre estas temáticas o son solidaridades que van decantando desde tus intereses y se terminan acercando en la propia escritura?

Programa no tengo. Me pasa que me interesan esas historias, de mujeres fuertes, de mujeres que han estado en un punto de máxima fragilidad y de algún modo se las arreglaron para salir de ahí. Te diría que me interesa el camino de la heroína, sólo por parafrasear, no es que me dedique a las heroínas. Soy una mujer, cuento cosas que me pasan y que les pasan a otras y que no le pasan a ninguna, pero que se me ocurren; lo que no es lo mismo que contar mundos femeninos exclusivamente: hago mundos que incluyen varones, sólo que no están en el primer plano que tienen generalmente, en las novelas y en el mundo.

Muchas gracias, Gabriela. 